\title{
El crepúsculo de los valores en la narrativa de Jorge Ibargüengoitia.
}

\section{The twilight of the values in the narrative of Jorge Ibargüengoitia.}

\author{
Víctor Díaz Arciniega \\ Universidad Autónoma Metropolitana (MÉXICO) \\ CE: vmda@correo.azc.uam.mx ID ORCID: 0000-0002-4884-5358 \\ Marisol Luna Chávez \\ Universidad Autónoma Benito Juárez de Oaxaca (MÉXICO) \\ CE: circe lamaga@yahoo.com.mx ID ORCID: 0000-0003-2799-6373
}

DOI: $10.32870 /$ sincronia.axxiii.n76.16b19

$\mathrm{BY}=\mathrm{NC}$

Esta obra está bajo una Licencia Creative Commons Atribución-NoComercial 4.0 Internacional

Recibido: $14 / 02 / 2019$

Revisado: 07/03/2019

Aprobado: 10/04/2019

\section{RESUMEN}

Sobre la base del estudio de Estas ruinas que ves (1975) y Las muertas (1977) de Jorge Ibargüengoitia, en este artículo se muestra como el autor percibe y valora la moral dentro de dos microcosmos representativos - ubicados en la provincia del Bajío- del México de mediados del siglo (1955-1965). A partir de esa recreación narrativa, en estas páginas se examinan dos perspectivas de la decadencia de los valores morales y la manera como afectan la interacción social a través de la ficción de dos dinámicas humanas, una encuadrada en el entorno de la clase media urbana ilustrada de Cuévano y otra en el entorno de la explotación sexual en burdeles en la misma imaginaria entidad federal. En esta pugna el tema de la moral y la violencia representan dos ejes simbólicos que le sirven 
a Ibargüengoitia para exhibir críticamente su percepción del proceso de cambio social dentro de ámbitos restringidos.

Palabras clave: Jorge Ibargüengoitia. Narrativa del medio siglo mexicano. Crisis de valores. Narrativa mexicana. Humor, sexualidad y narración en México.

\begin{abstract}
:
On the basis of the study of Estas ruinas que ves (1975) and Las muertas (1977) of the author Jorge Ibargüengoitia, this article shows how the author comprehends and appraises the moral within of two microcosmos representative - located in the bajio region- of mid-century Mexico (1955 - 1965). From this narrative recreation, in these pages, two prospects are examined, one the decadence of the moral values and two, the way how affects the social interaction through the fiction of two human dynamics, framed in the environment of the illustrated urban middle class of Cuévano and another in the environment of sexual exploitation in brothels in the same unreal state. In this struggle, the issue of morality and violence represent two symbolic ideas that help Ibargüengoitia to critically show his perception of the process of social change within of restricted areas.
\end{abstract}

Keywords: Jorge Ibargüengoitia. Narrative of the Mexican half century. Crisis of values. Mexican narrative. Sexuality and narrative in Mexico.

\title{
Introducción
}

La literatura dramática y narrativa de Jorge Ibargüengoitia (Guanajuato, 1928 - Mejorada del Campo, próxima a Madrid, 1983) ${ }^{1}$ goza de notabilísimo y fiel público lector, como ilustran las abundantes reimpresiones de su teatro, sus novelas y sus crónicas y ensayos periodísticos; entre los estudiantes de educación media, media superior y superior goza de prestigio, en particular porque los temas y tratamientos les resultan accesibles, tanto que con frecuencia algunos de sus dramas son llevados a escena en los teatros estudiantiles. Las novelas con temas histórico, por ejemplo Los 
relámpagos de agosto (1964) o Los pasos de López (1982), son utilizadas en las escuelas como apoyo pedagógico para abordar la guerra de Independencia o la Revolución.

En esa extensa y consistente fama de la literatura de Ibargüengoitia, reconocemos que esos lectores perciben con nitidez la sugerente colección de tipos y entornos sociales e históricos recreados dentro de convenciones promedio fácilmente identificables. Los recursos paródicos de Ibargüengoitia son precisos y eficaces, y sobre ellos descansa buena parte de su fama. Sin embargo, cuando conversamos con esos lectores e indagamos hasta dónde se percibió y valoró el sentido crítico del dramaturgo y narrador, nos sorprende advertir que son pocos quienes rebasan la línea promedio de las anécdotas, como si el fin último fuera el humor por sí mismo. ${ }^{2}$

En las dos novelas que examinaremos a continuación, Estas ruinas que ves (1975) y Las muertas (1977), Jorge Ibargüengoitia incorpora como el centro de su crítica los temas que había venido exponiendo con detalle en la mayoría de sus obras de teatro: el adulterio femenino, la incapacidad masculina por desempeñar un trabajo, la indolencia de los jóvenes, todo lo cual sumado a la falta de oportunidades y la doble moral de la provincia, como lo más sobresaliente. ${ }^{3} \mathrm{~A}$ pesar del cambio en el uso del género literario - antes teatro, ahora novela-, observaremos que los recursos utilizados para la creación del suspenso son prácticamente idénticos: el ahora narrador plantea el desarrollo de un malentendido que se resuelve al final de la novela sin ninguna repercusión grave para los protagonistas (Estas ruinas que ves) o para cerrar un ciclo de aparentes casualidades sin orden ni sentido (Las muertas).

Podemos decir, sin temor a equivocarnos, como en distintas ocasiones en el teatro surgieron los dramas que alcanzarían su maduración en la narrativa, y que se resolverían en términos equivalentes en el teatro, pues el drama que debería estallar al final de la historia, se suaviza mediante la ridiculización de los propios acontecimientos: se convierten en una escena grotesca, seguida de la aceptación de todos los protagonistas, ya sea por timidez o por pereza. Por lo tanto, podemos afirmar que, en ambos géneros, teatro y novela, Jorge Ibargüengoitia planteó el desarrollo de un melodrama moral humorístico (con acento paródico en Estas ruinas que ves (1975) y corrosivo en Las muertas (1977)), en tanto que el encubrimiento de las faltas humanas se convierte 
en una necesidad vital, útil para una convivencia mediocre y apacible: es el marco de una aceptada moralidad en donde aparentemente nadie comete ninguna transgresión.

Esta construcción dramática ocurre con obviedad en Estas ruinas que ves, novela que tiene su antecedente más cercano en Susana y los jóvenes y Clotilde en su casa, obras en las que se desarrollan los dramas más importantes experimentados por las protagonistas de la novela, Gloria y Sarita, que de manera similar viven las imposiciones sociales de un entorno convencional. Estructuralmente, Estas ruinas que ves es una novela linealmente simple -a diferencia de la complejidad de Las muertas-: tiene un solo narrador y una sola secuencia anecdótica ordenada cronológicamente de principio a fin sin casi ninguna digresión. Esto permite que el interés del lector, así como la intriga que maneja el narrador, pueda basarse en una confusión en apariencia simple, pero que va haciéndose más compleja a medida que la novela avanza: la supuesta enfermedad cardíaca de Gloria, la joven más deseada de la pequeña comunidad de Cuévano. Cuando finalmente la intriga se revela, la mayor parte de los acontecimientos importantes ya ha sucedido, y el protagonista se ve atrapado en la dinámica social de este lugar, dentro de la cual, al aceptar sus reglas, se ha convertido en uno más de ellos.

La novela inicia con una descripción general del paisaje cuevanense; a éste se añade la relación de su pasado minero, que fue la fuente de riqueza del lugar y al cual se debe el asentamiento de las familias más importantes y poderosas de las que ahora sólo quedan recuerdos. A esta riqueza los cuevanenses atribuyen también el desarrollo intelectual de sus más preclaros habitantes, un conjunto de sabios que se han destacado en diferentes áreas del pensamiento. Estos antecedentes sirven para enfatizar la decadencia moral y económica de una sociedad empeñada en vivir del pasado, a través de las viejas glorias locales y de mantener una conducta atada a las reglas de la convención.

\section{Desde su título}

En Estas ruinas que ves se hace referencia alusiva al fenómeno de la decadencia económica y moral, que se ve "amenazada" por un grupo de gente joven, con impulsos eróticos y necesidades vitales 
que no serán del todo satisfechas en esa estrecha comunidad. El narrador y protagonista de la novela ha llegado recientemente a Cuévano contratado por la universidad para impartir clases de literatura. Por ser descendiente de un ilustre cuevanense, pasará a formar parte de la élite local, que se compone por otros profesores de la universidad, un par de estudiantes destacados y algunas familias de renombre. En las primeras páginas de la novela el principal objetivo del narrador es destacar por qué la pequeña ciudad de Cuévano permanece inmutable con el paso de los años, y esto se debe, según él explica, a la obediencia ciega de la misma rutina:

En Cuévano hay algo que produce en el observador la sensación de que lo que está viendo no es acontecimiento único, sino acto ritual que se ha repetido todos los días a la misma hora desde tiempo inmemorial y se seguirá repitiendo hasta la consumación de los siglos. (Ibargüengotia, 2005a: 22-23)

La actividad general, académica y comercial, inicia a las nueve y media de la mañana y se caracteriza por reproducir los mismos acontecimientos con los mismos personajes: un borracho tirado afuera de una cantina, el cura hablando con la misma beata, el gerente del banco local conversa con el rico del pueblo, etc.

Dentro de este "orden" que el narrador descubre rápidamente y al que pronto se adapta, existe una estructura social todavía más arcaica: la que regula las relaciones públicas y privadas de los hombres y las mujeres. Estas normas son inflexibles, y la ruptura de una de ellas da lugar a un malentendido que puede destruir el bien más preciado de una mujer: su reputación. En la universidad, el medio aparentemente más abierto de toda la comunidad, también se muestra la práctica de estas costumbres; por ejemplo, se dice que Pascual Requena, uno de los rectores de la universidad impidió que en las clases de dibujo se impartiera el tema del desnudo femenino con la justificación de que "no quería herir las susceptibilidades de las señoritas estudiantes" (27). También es una falta de respeto, por ejemplo, que los hombres se expresen con malas palabras frente de las damas presentes, pero la regla que va a ser contundente y dará lugar a toda una serie de malentendidos y ocultamientos es la que confiesa la madre de Gloria, doña Elvira, quien al 
quedar a solas con su hija y el protagonista durante una reunión de la universidad, señala categóricamente: "no es bien visto que a dos mujeres solas se les vea platicando con un joven que no es ni novio de una ni marido de la otra". (33)

El narrador, atraído desde un principio por la belleza de Gloria, siente el deseo de seducirla, pero los obstáculos para que eso ocurra son múltiples, empezando por la presencia de los padres de la joven, quienes ejercen una vigilancia permanente; pero pronto el narrador descubrirá que su contendiente más difícil de vencer es Rocafuerte, el novio de Gloria, quien pretende cerrar un importante negocio que consiste en la venta de unas computadoras; una vez que este asunto esté resuelto, Rocafuerte pedirá la mano de Gloria. La aprobación del novio de parte de los padres de Gloria es obvia y está basada en la pericia del novio para la realización de sus negocios. Como ocurrió en Susana y los jóvenes cuando Alfredo, el pretendiente potencial con mejor porvenir, se declaró a Susana, la madre de ésta cambió radicalmente, hasta concederle la importancia de un miembro más de la familia. En Susana y los jóvenes la muestra de aceptación del novio ocurrió cuando a Alfredo su futura suegra lo dejó pasar a la sala familiar, expulsando de ésta al padre de la novia. En estas ruinas que ves el estatus del novio que va a formalizar la relación con la joven también se manifiesta a través de sucesos cotidianos:

un día [...] el Doctor se llevó el periódico y las pantuflas a otro cuarto para dejarlos solos a él y a Gloria. En otra ocasión la Rapaceja le dijo a su hija: "lleva al ingeniero al fondo de la huerta para que vea el rosal de Castilla." (Ibargüengotia, 2005a: 57)

El hecho de que los acontecimientos más significativos ocurran alrededor de su noviazgo, hacen que la educación de Gloria sea sumamente superficial; en otras palabras, los años de estudio son una preparación para su ocupación más importante: el matrimonio. Por lo tanto, no se considera que la educación universitaria sea en realidad una formación para un futuro profesional. Su currículum escolar, como lo señala el narrador, tiene las mismas limitaciones que todas las cuevanenses: 
primaria y secundaria con las madres redentoristas, preparatoria en la ciudad de México, con las hermanas del Divino Verbo, después sus padres habían querido que aprendiera inglés y la habían mandado dos años a Houston con las monjas adoratrices. (Ibargüengotia, 2005a: 60)

Esto significa que los padres se han preocupado por darle las herramientas indispensables, en las que el conocimiento escolar o académico no es una prioridad y sí la religión para que mantenga los efectos represores sobre su sexualidad, cuyo desarrollo es el mayor peligro que enfrenta una cuevanense, y que explica en gran medida la prisa de los padres por casarla con Rocafuerte, el mejor novio que Gloria ha tenido hasta el momento.

La intriga que se resolverá hasta el final de la novela: la supuesta afección cardiaca de Gloria, juega un papel fundamental en la tensión erótica establecida entre ésta y el narrador, pues es de su conocimiento que ella podría morir al alcanzar el orgasmo, lo que impide que el narrador se decida a seducirla, a pesar de las varias oportunidades de hacerlo. Cuando finalmente el narrador se entera que la enfermedad de Gloria no existe, las oportunidades de cualquier encuentro sexual han desaparecido, por lo cual el narrador teme "haberla perdido para siempre". El ejemplo más evidente ocurre cuando Gloria y el narrador investigan la colección de libros de Leonardo Begonia, en la casa de sus hermanas, sus herederas. En ese momento, dejándose llevar por sus impulsos, el narrador tiene la osadía de propasarse con Gloria; a pesar de su relativo abuso, ella no se enfurece, sino que explica: "no siga. Que soy una mujer muy apasionada", así da lugar a que el narrador continúe. Sin embargo, como el narrador está convencido de la enfermedad de su amiga, se contiene pensando en que la conquista podría llevarla a la tumba.

Pese a todos los juicios que el narrador elucubra a lo largo de la novela sobre la apariencia virginal de su alumna, que contrasta con su poder sensual varias veces explícito, el verdadero carácter de ésta se revelará hacia el final de la novela. El detonante de este hecho es una situación aparentemente simple: la proyección de una película "indecente" en un cine Cuévano, una ciudad pequeña, donde no se permite la menor afrenta de la moralidad ni siquiera a través de un medio fílmico. El tema de la película es escandaloso porque recrea la historia de una mujer que tiene un 
amante con el consentimiento del esposo, sin que la amistad entre éstos sufra ninguna fisura a pesar de estar enterados de que comparten a la misma mujer.

Gloria se empeña en defender el argumento de esta película delante de sus padres, los cuales se encuentran ofendidos desde el momento en que ella se presentó con el novio a ver semejante exposición de decadencia moral. Para colmo, Rocafuerte se empecina en darle la razón a su novia, en lugar de coincidir con sus futuros suegros. Este hecho es una provocación para los padres de Gloria, y así responden:

¿Aprueba usted que un hombre, que tiene esposa, y ella se va con su mejor amigo, no le haga reclamación alguna a éste? No sólo no le hace reclamación, sino que sigue siendo su amigo, como si nada hubiera pasado. ¿Aprueba usted eso? (Ibargüengotia, 2005a:147)

Este episodio, aparentemente trivial, incide de manera peculiar en otros adulterios, esta vez no ficticios, sino reales y cercanos a la élite cuevanense, los cometidos entre el narrador y Sarita, primero, y entre Malagón y Sarita, después. La relación entre el narrador y Sarita se establece casi durante toda la novela; inicia en el momento cuando ella se presenta a la elaboración de los murales con su marido y sin ropa interior, y concluye cuando a través de la sirvienta perspicaz de los Espinoza se da a conocer su indiscreción, lo cual da por terminado el intenso romance entre Sarita y el narrador.

En gran medida, la relación que se establece entre Sarita y el narrador es propiciada porque el narrador no puede seducir a Gloria. Una vez que éste descubre que su relación está a punto de ser descubierta decide romper con Sarita, pero ésta sin dejar pasar mucho tiempo consigue pronto un sustituto, Malagón, quien resulta torpe y es rápidamente descubierto por el esposo. El tema de la película proyectada en Cuévano es, por lo tanto, una versión de lo que ocurrirá entre estos individuos. Al igual que ocurrió en Clotilde en su casa, en donde el marido engañado tenía que enfrentar las consecuencias frente a la familia y las amistades, en Estas ruinas que ves el adulterio tiene que ser asumido frontalmente por el esposo engañado, aunque éste conozca -o por lo menos intuya - su situación desde el principio. Cuando sale a la luz el adulterio, Espinoza no tiene 
otro remedio que aceptar su vergüenza, porque es demasiado pusilánime para enfrentar al amante, para exigir el divorcio o para ventilar su vergüenza ante la sociedad cuevanense. Como ocurre en Clotilde en su casa, en donde el esposo descubre a su mujer y al amante en su propia casa, la escena en que el adulterio es revelado sirve para degradarlo y ridiculizarlo en grado extremo, al punto que el esposo nunca recupera su dignidad.

En Estas ruinas que ves, sin embargo, la escena cobra un giro notablemente más retorcido, pues el marido engañando cuenta con la anuencia de los amigos que encubren esta situación. Aquí el encargado de "reestablecer" el orden moral es Sebastián Montaña, quien resuelve el conflicto así:

no voy a tratar de demostrar que la actitud de Isidro -Malagón- no sea reprensible. Lo es, y mucho. ¿Pero quién de nosotros no ha sido víctima de vez en cuando de sus malas pasiones? ¿Quién no ha sido tentado por el demonio de la carne? ¿Quién no ha caído en la tentación? (Ibargüengotia, 2005a:171)

De esta manera es resuelto el problema e incluso la situación de Sarita queda aclarada: “¿Qué ha pasado en realidad? Nada absolutamente. Tu honor, Espinoza, está a salvo. Y te lo decimos todos los que estamos aquí. ¿Gracias a quién? A Sarita, tu esposa, que se portó con una discreción admirable". (171) Así queda solucionada la falta, de manera que los acontecimientos siguen su curso sin que haya ninguna alteración de la rutina ni de las relaciones ni personales ni profesionales.

Al final, Gloria decide enfrentar a sus padres y separarse de ellos durante el lapso en que contraerá matrimonio con Rocafuerte. Este cambio de planes ocurre por el escándalo que su madre propicia en una reunión de profesores en la casa de los Espinoza. Así, éstos dejarán la casa en manos de Gloria, quien podrá libremente recibir a quien ella desee sin la supervisión ni de sus padres ni del novio. El desenlace de la novela nos permite pensar que, una vez aclarado el malentendido de la enfermedad cardíaca, el narrador tendrá la oportunidad de hacerla su amante, utilizando la misma estrategia que utilizó con Sarita. Es decir, el mismo ciclo de engaños y ocultamientos vuelve a ocurrir con el cambio de muy pocos matices. Es en voz del mismo 
Rocafuerte que Toño, el narrador, se entera de que Gloria nunca ha estado enferma y de que ha disfrutado de su sexualidad sin ningún prejuicio, mientras éste se ha contenido durante toda la novela:

mira, Gloria sí puede resistir el orgasmo. Aquí arriba, en mi cuarto, ha resistido por lo menos unos quince. En la huerta de su casa, cerca del rosal de Castilla, también resistió el orgasmo, y en los jardines del doctor Cruchet también ha resistido el orgasmo varias veces. (Ibargüengotia, 2005a:180)

El carácter del narrador nos permite intuir que en realidad él no es un conquistador, más bien las mujeres lo eligen como un entretenimiento pasajero, que aligere un poco la rutina de sus vidas y la estupidez o la indiferencia de sus maridos. En el catálogo de los personajes masculinos ninguno parece satisfacer a sus parejas, a pesar de que ellos están convencidos de su felicidad conyugal. Las mujeres, a su vez, no se quejan abiertamente, pero sucumben con rapidez a las propuestas directas o a las insinuaciones de los amigos de sus esposos o novios, dejando en claro que sus deseos están permanentemente insatisfechos y que contemplan la posibilidad de una relación extramarital como un acto de profilaxis cotidiano, que no debe tener ninguna trascendencia. Así, las relaciones se convierten en un trato superficial, en las cuales es una prioridad ceñirse a las reglas del entorno, cuidar los intereses conyugales y mantener ocultos los verdaderos deseos.

\section{La estructura narrativa}

Es más compleja en la novela Las muertas, como lo mencionamos al principio de esta exposición, sobre todo porque no existe un solo narrador que dé cuenta de todos los acontecimientos, como en Estas ruinas que ves, sino que el trabajo narrativo se divide entre las distintas voces de los protagonistas, que narran desde su punto de vista, y casi con sus palabras, los hechos que presenciaron. En términos generales podemos decir que existen por lo menos tres historias centrales: la primera se desarrolla en torno a la relación que surgió entre Simón y Serafina Balandro, 
la segunda se ocupa de describir la historia entre el capitán Bedolla y Serafina y, la tercera, que es la narración de cómo fueron fundados y cómo operaban los burdeles de las hermanas Balandro.

Subordinadas a estos ejes nucleares se encuentran otras historias, breves narraciones dedicadas a dar a conocer los acontecimientos que determinaron la vida de estas mujeres, las pupilas de las Balandro, quienes en su mayoría indefensas e ignorantes, formaron parte de esa red de prostitución mucho antes ser conscientes de pertenecer a ella. La multiplicación de las voces narrativas tiene un efecto estético fundamental: articular la historia de las Balandro sin seguir una línea cronológica estricta, de principio a fin; a diferencia de Estas ruinas que ves, la estructura narrativa de Las muertas es cíclica, termina casi en el mismo punto donde comienza, con la narración de Simón Corona, lo que a final de cuentas viene a reforzar el sentido causal de la novela, que refiere la condición de las Baladro como una acumulación de crímenes y malas decisiones. ${ }^{4}$

De varias maneras, Las muertas viene a cerrar temáticamente el ciclo del teatro y la narrativa que hemos analizado hasta ahora; si en el resto de las obras novelísticas anteriores se centraban en el tema de la familia y la doble moral, ${ }^{5}$ en este caso se muestran las condiciones extremas que genera este fenómeno, pues a través de las hermanas Balandro y de sus centros de prostitución es donde se revela la decadencia de los valores y la inexistencia de un sistema que proteja a la población femenina más vulnerable, siempre ilegal y de salud expuesta a las peores atrocidades. De una forma contundente, como lo vimos antes en las obras de teatro de carácter histórico La conspiración vendida y El atentado, e incluso en la obra dramática de ficción Los buenos manejos, Jorge Ibargüengoitia criticó la ineficacia y la corrupción de un sistema político que se encuentra a disposición de los intereses que proteja a una élite. ${ }^{6}$ En este caso, el fenómeno se repite con consecuencias trágicas porque causó la degradación, la humillación y la muerte de un grupo de mujeres.

Por paradójico que resulte, el desenlace de las Baladro sólo ocurre como consecuencia de la necedad de Serafina, quien enamorada y abandonada por Simón Corona, decide tomar venganza contra su ex amante, mucho tiempo después de que el romance había terminado e incluso tras haber sostenido una relación con otro hombre, el capitán Bedolla. La novela inicia con este 
episodio, cuando finalmente Serafina llega a la panadería de Simón Corona, acompañada de los compinches que la han seguido durante su carrera delictiva; protegida por éstos, Serafina balacea la panadería en la que se encuentra el dueño y una ayudante, pero sin causar la muerte de ninguno. Este hecho afectará radicalmente la vida de todos los ahí presentes, al grado que derivado de estos acontecimientos se precipita el desenlace de la novela.

Este primer acontecimiento además sirve para exponer el modelo narrativo que la novela va a mantener la mayor parte del tiempo: el interrogatorio. A través de éste, los personajes podrán declarar con cierta libertad las diversas circunstancias que los ligaron a las Baladro. También sirven los interrogatorios como una forma paródica de ridiculizar los procesos de la justicia mexicana, fácilmente enredada en un lenguaje ineficaz y redundante, como cuando Simón Corona rinde su declaración y ésta se ve destinada a ser trasmitida de una a otra instancia antes de cumplir su objetivo:

el agente hizo el trámite de costumbre, que consistía en dar parte a sus superiores, señalar a la presunta responsable y pedir al C. Procurador del Estado de Mezcala que pidiera al C. Procurador del Estado de Plan de Abajo que pidiera al agente del Ministerio Público de Pedrones que pidiera al jefe de la policía del citado pueblo, que aprehendiera a la Sra. Serafina Baladro. (Ibarguengoitia, 2005b:13) ${ }^{7}$

\section{El negocio de la prostitución}

Si bien es sabido que prosperó en gran medida por la doble moral de esa sociedad, también lo es que para que éste creciera debió contar con el respaldo de una corrupción ya institucionalizada. Desde un principio, las hermanas Baladro recibieron el apoyo de algunos personajes de la policía y, después, con la tácita anuencia mediante la asistencia de ciertos personajes de la política en sus tugurios fue como lograron consolidarse, aunque, paradójicamente, las faltas de organización y prevención en estos lugares fue lo que desencadenó su ruina. Como era claro en Los buenos manejos, cuyo centro temático ocurre en torno a tres prostitutas que llegan al pueblo con la finalidad de establecer un burdel y, finalmente, lo consiguen después de aliarse con las figuras de 
importancia del pueblo, en Las muertas será indispensable el auxilio de las autoridades corruptas que participarán en el levantamiento del negocio e incrementarán su prosperidad. En su momento de auge, durante la inauguración del Casino del Danzón, las figuras prominentes de la política y la economía local tienen la función de legitimar y respaldar el tugurio de las Baladro; se describe así a los que asistieron a la fiesta:

...estaban el licenciado Canales, secretario particular del Gobernador en el Estado de Mezcala, el diputado Medrano, un líder ferrocarrilero y dos líderes campesinos, el gerente del Banco de Mezcala, [...] varios comerciantes y el dueño de un establo que tenía más de cien vacas. (Ibarguengoitia, 2005b, p. 49).

De igual manera, en este sentido, juegan un papel fundamental las parejas de Serafina Baladro, Simón y el Capitán Bedolla, porque el despecho que uno produce funciona como una consecuencia determinante para que el segundo se involucre en el negocio de las hermanas. Serafina y Simón sostuvieron una tortuosa relación durante varios años, en los que se juntaban y separaban sin motivo aparente. Durante este lapso, las Baladro ya tenían un primer burdel y algunas pupilas, y éste fue uno de los hechos que hizo creer a Serafina que no era digna del amor de Simón, que ella ejerciera el lenocinio. Éste vivía encerrado en la casa de ella, sin trabajar ni participar en las actividades del burdel (en esa época funcionaba el México Lindo); a veces, nostálgico de su oficio y de su tierra, quería irse de ahí, pero las influencias de Serafina con la policía propiciaban que lo encarcelaran y por eso él prefería quedarse escondido. Fue hasta que hicieron un viaje a Acapulco cuando Serafina decidió, en un arranque de amor y sinceridad, confesarle a Simón que ella era la responsable de los diversos arrestos de los que había sido objeto. Él, decepcionado, decidió abandonarla, ahora sí definitivamente; esto causó el deseo de venganza y produjo una profunda depresión en Serafina, que duró casi mes y medio y concluyó cuando ésta conoció a Bedolla. Durante este periodo de soledad, se describe que ella:

tenía insomnio. Pasaba el final de las noches y el principio de las mañanas con los ojos abiertos, enfrascada en diálogos imaginarios con Simón Corona. En ellos le reclamaba su 
ingratitud, le demostraba que todo lo que había hecho había sido en beneficio de él, le hacía lista de los favores que le debía. (Ibarguengoitia, 2005b, p. 30)

En esas fechas, circunstancialmente, el capitán Bedolla se enteró que Humberto Paredes, el único hijo de Arcángela Baladro, era el dueño de un plantío de marihuana, por lo cual se dio a la tarea de aprehenderlo. Sin embargo, antes de llevarlo preso, Bedolla prefiere primero ir a visitar a su madre, la cual en un primer momento no cree lo que relata Bedolla. Sólo hasta después de un rato de dudas es que Arcángela decide hacer la confesión:

ella, que hubiera querido que su hijo estudiara medicina, que se había sacrificado separándose de él, para que el niño no tuviera malas influencias y se convirtiera en un hombre de provecho, que había pagado una fortuna en colegiaturas, se veía ahora ante la terrible realidad: su hijo era traficante de drogas. (Ibarguengoitia, 2005b: 33)

Así, en este primer momento, el capitán Bedolla "rescata" a Humberto, aunque éste trágicamente muere más tarde como consecuencia de su vida criminal. Este primer acercamiento con Arcángela sirve para que después ésta le presente a Bedolla a Serafina, cuando ella anda en busca de alguien con quién comprar una pistola para descargar su odio contra Simón Corona. Sin embargo, en cuanto Bedolla comienza a cortejar a Serafina, a ésta se le pasa su crisis de despecho, y olvida, durante un lapso muy prolongado, el abandono del que fue víctima:

se dio cuenta de que le costaba trabajo acordarse de Simón Corona, de que ya no le interesaba la venganza y se arrepintió de haber gastado mil doscientos pesos en una pistola que la dejaba sorda después de cada disparo. (Ibarguengoitia, 2005b: 37)

Con la aparición de Bedolla en las vidas de las Baladro, las condiciones del negocio cambiarán drásticamente, porque él se convertirá en una de sus partes más activas. Será él quien funja como el representante de las hermanas frente a las autoridades, será el enlace entre los proveedores y las dueñas y será el ejecutor de los castigos corporales que sufrirán las pupilas en la última parte de la novela. Si la versión que tenemos de Simón Corona es lamentable, pues es un hombre irresponsable 
e indolente, el retrato de Bedolla es aún más siniestro. Se supone que tiene esposa e hijos, pero no es fiel ni buen proveedor, e identifica a las Baladro y sus lupanares como una forma de hacerse rápidamente de dinero a través de la corrupción y la explotación de las prostitutas.

Corona y Bedolla, aunque con características aparentemente diferentes, viven del trabajo de las mujeres y no son capaces de ejercer ninguna actividad honrada que les dé para vivir y para mantener su hogar; ambos tienen diferentes mujeres pero nunca se hacen responsables ni de ellas ni de sus hijos. Esta imagen de la masculinidad la viene a cerrar Humberto Paredes, el hijo traficante de Arcángela, quien a pesar de haber invertido grandes sumas en su educación, parece heredar la avaricia de su madre. Ésta, preocupada porque él no se entere de dónde proviene el dinero con el que lo mantiene, lo conserva alejado de ella, pero rápidamente él comete un crimen en la Facultad de Medicina, atacando a un compañero. El delito es minimizado gracias al dinero de Arcángela. Tras unos años de estudio en Estados Unidos, donde se supone que su madre lo envió a estudiar inglés, Humberto no sólo fracasa en los planes que su madre le había deparado, sino que también regresa convertido en un delincuente.

Sin embargo, el desenlace de Humberto no ocurre debido a su reciente carrera delictiva, sino a su relación con Conchita, una joven que conoce cuando regresa a México; ella es totalmente diferente a él. Pertenece a una familia sencilla y conservadora que le inculca llegar virgen al matrimonio y mantener una conducta de decencia, por eso, cuando Humberto pretende propasarse con ella, su desconcierto es mayúsculo. Después se entera del pasado de Humberto y de las actividades de su madre y su tía, y sus hermanos le prohíben tener una relación con él. Se sospecha, aunque no se sabe con certeza, que fueron éstos los que mataron a Humberto, ante la consternación de todo el México Lindo, lugar en el que murió este individuo.

Este hecho será decisivo porque precipitará el descenso de las Baladro, pues cuando Humberto muere el lugar es clausurado. De cualquier manera, este trío de personajes masculinos revela el estado crítico de la masculinidad, la cual está siempre protegida por mujeres fuertes, ambiciosas y controladoras, las Baladro, quienes son las encargadas de hacer prosperar el negocio a través de diferentes infamias, pues si bien son apoyadas por figuras masculinas, también son ellas las 
verdaderas orquestadoras de los tugurios, reconociendo que "el negocio de la prostitución es muy sencillo, lo único que se necesita para que salga bien es mucho orden". (40)

De esta manera, Arcángela Baladro describirá las reglas para el buen funcionamiento de los burdeles. A las ocho de la noche se abren las cortinas para dejar entrar a los clientes, a esa hora todo debe estar listo: el lugar limpio y las muchachas arregladas. La regla de oro es que los clientes consuman, alcohol o el servicio de las mujeres, de preferencia ambos. Las prohibiciones no son muchas pero están totalmente encaminadas a generar ganancias para la casa:

está prohibido que las muchachas cobren por bailar, está prohibido sentarse en una mesa sin consumir. Al servir una tanda el mesero tiene la obligación de entregar al cliente la nota del consumo y a la muchacha su ficha. Al terminar su visita el cliente tiene la obligación de pagar la cuenta, con buen modo y dinero en efectivo. (Ibargüengoitia, 2005b: 41)

En este mundo todo está reglamentado y, paradójicamente, en el desorden moral también hay cierto orden que, al salirse de la convención, propicia la caída de las Baladro. Este acontecimiento ocurre durante la inauguración del Casino Danzón, un tugurio construido explícitamente para funcionar como tal, con escenarios extravagantes y cuartos específicamente diseñados para las tareas de las mujeres, y que acabará siendo el refugio de las Baladro y sus trabajadoras cuando les son clausurados todos sus otros negocios. En este lugar también se llevarán a cabo la mayoría de las atrocidades cometidas en contra de las prostitutas. El episodio que detonará todo ocurre cuando el licenciado Sanabria decide sacar a bailar a Escalera, uno de los hombres de confianza de Arcángela, "ante las miradas horrorizadas de todos los presentes". (50) Después de esto, intenta bailar con otros hombres, pero éstos no aceptaron la invitación, por lo cual, rechazado y ridiculizado, desarrolla una aversión especial por las Baladro, a quienes responsabiliza de su deshonra; al retirar su apoyo hacia ellas, Sanabria las dejará completamente solas inmersas en una serie de acusaciones y pruebas que finalmente las condenará.

El tema de la homosexualidad surge pocas veces en la obra de Ibargüengoitia o se presenta solamente en forma de insinuación (como ocurre en el caso de la obra La lucha con el ángel, en 
donde aparece el personaje Gil, un soltero que tiene una amistad sospechosa con el protagonista que concluye cuando éste se casa precipitadamente con Carmen). Aunque sea un mundo al revés, como ocurre en el caso de Las muertas, es suficiente para crear una imagen de animadversión hacia el hombre que decide mostrar abiertamente sus preferencias sexuales ante una sociedad machista, que condena de forma radical no sólo que los hombres tengan deseos hacia otros hombres, sino que se atrevan a manifestarlo públicamente.

No ocurre lo mismo con la homosexualidad femenina, hacia la cual existe cierta tolerancia, al grado que, en el Casino Danzón, cuando se suscita el pleito entre Evelia y Feliza, una pareja de prostitutas que son "amigas del alma", o sea amantes, toda la comunidad se mantiene al margen al considerar que el asunto es de índole "privado". Como consecuencia de este lío, ambas mueren al caer por el balcón que nunca fue convenientemente asegurado. Poco tiempo después se dará a conocer que el Casino Danzón, el único tugurio que había sido “planeado" por sus dueñas y para cuya construcción se había incluso contratado a un arquitecto, tampoco era un lugar que brindara la seguridad, la higiene y la comodidad necesaria para los clientes y las trabajadoras. Como todo en la vida de las Balandro, incluso la construcción de este centro de prostitución, fue un episodio precipitado, diseñado por el sueño delirante de sus dueñas, pero nunca siguió una regla estricta ni en el diseño ni en la estructura de burdel que se pretendió inicialmente.

\section{La abyección humana}

Se retrata de la manera más cruda en la novela Las muertas de Jorge Ibargüengoitia, aunque incluso aquí existe una gradación en el nivel de la corrupción que va incrementándose a medida que el relato avanza. Al principio de la narración, por ejemplo, en el capítulo titulado "Historia de las casas", se describe la historia subordinada de la empleada Herminia; en este apartado se señala el modus operandi de las Baladro, quienes solían llevarse a jóvenes inocentes e inexpertas de los poblados cercanos a Pedrones con la promesa de conseguirles un trabajo de sirvientas. Era hasta que estas mujeres llegaban a los burdeles cuando se enteraban de la verdadera naturaleza de la profesión y de los sacrificios que tenían que hacer para "devolver" los favores recibidos de las 
hermanas Baladro. Entre éstos se encontraba el pago del alojamiento, la comida, el vestuario y el dinero que supuestamente Serafina enviaba a los familiares de las jóvenes, los cuales, por supuesto nunca recibían ninguna compensación económica; al mantenerse separadas de sus familias por la vergüenza que su trabajo les inspiraba, las prostitutas se enteraron, hasta muchos años después, de las dimensiones de la estafa de la que fueron víctimas.

Sin embargo, el grado de avaricia de las Baladro se incrementará a medida que el negocio va sufriendo reveses. La prueba de este declive puede encontrarse en la historia de Blanca, casi a la mitad de la novela, donde se describe el punto más crítico del drama y se expone plenamente la corrupción, la indolencia, la ignorancia y la bajeza moral de este tipo explotación sexual a cargo de unos pocos, quienes prácticamente son dueños de los cuerpos y las vidas de un grupo de personas desafortunadas. Blanca, al igual que las otras muchachas, fue llevada con engaños a trabajar con las Baladro, fue vendida en cuatrocientos pesos por su madre y por una intermediaria entre las madres y las proxenetas, una mujer llamada Juanita.

Blanca era paradójicamente negra y su único defecto era tener los dientes manchados, como todos los habitantes de su pueblo originario. Este hecho va a marcar una importante consecuencia en el curso de la novela, pues una vez que Blanca ha reunido dinero suficiente se cambia los dientes por unas prótesis de oro, las cuales van a ser la manzana de la discordia que propicia la discusión entre Evelia y Feliza, la pareja que muere al caer del balcón. Se dice que Blanca era una empleada eficaz, que era una conocedora de su oficio y que no causaba problemas entre sus compañeras. Su desgracia fue quedar embarazada y recurrir a la Calavera, una de las fieles servidoras de Serafina y Arcángela, quien era la que aplicaba remedios caseros a las empleadas a falta de un servicio médico medianamente digno. La Calavera le administró un té abortivo que fue completamente ineficaz y por eso tuvo que recurrir a la intervención del doctor Arellano, quien se arriesgó a practicar el aborto a pesar del estado avanzado del embarazo.

Aunque el aborto aparentemente funcionó, la operación fue totalmente catastrófica, al grado de causar una parálisis en la paciente y dejarla lisiada de por vida. El deseo de evitar los costos de hospitalización propició que Blanca fuera abandonada durante un lapso muy largo, hasta 
que fue rescatada por Libertino, un cliente regular de Blanca en el México Lindo. Posteriormente, la Calavera se llevó a Blanca del Hospital Civil, aunque prácticamente postrada, desfigurada y afectada de sus facultades mentales. Ya viviendo en la clandestinidad en el Casino del Danzón, la Calavera decidió consultar a una curandera para resolver el problema de la parálisis de Blanca; asistida por Ticho, uno de los achichincles de Serafina y Arcángela, la Calavera ató a Blanca a unas mesas en el centro del cabaret con el objetivo de llevar a cabo la supuesta curación que consistía en aplicar una plancha caliente en el rostro afectado de la enferma. Debido al esfuerzo recibido y a la brutalidad a la que es sometida, Blanca finalmente muere.

Otra vez, movidas por la avaricia y por la ilegalidad en la que murió Blanca, las Baladro deciden cavar su primera fosa clandestina, que apenas es lo suficientemente profunda para ocultar el cadáver. Para esta época, Serafina y Arcángela comienzan a reconocer que no recuperarán el negocio y que difícilmente convencerán a las autoridades de reabrir sus casas de prostitución. Durante la última tercera parte de la novela, en donde se describe el hundimiento de las Baladro, se intensifica también la violencia y las atrocidades; las proxenetas se van volviendo más viles a medida que desaparecen las posibilidades de restaurar el negocio. En algún momento deciden incluso vender a algunas trabajadoras al dueño de otro cabaret, pero finalmente se arrepienten al no conseguir el precio que ellas pretendían. Así, se refugian en el Casino del Danzón, pero el encierro y la falta de alimentación exacerba las tensiones entre las empleadas, al grado que comienzan a cometer infracciones que son seriamente castigadas por las Balandro y Bedolla. Consecuentemente, lo que en un principio era sólo explotación se vuelve esclavitud al degradar al extremo a las mujeres y quitarles cualquier asomo de dignidad.

El homicidio se consuma a través de Teófilo Pinto, el esposo de Eulalia, la otra hermana de Serafina y Arcángela. Al principio de los negocios de sus hermanas, Eulalia se rehúsa a formar parte de ellos y rechaza rotundamente establecer algún vínculo con ellas. Pero un tiempo después, ella y su marido comienzan a tener serias dificultades económicas, es ahí donde Arcángela le pide a Teófilo que se haga cargo de cuidar el rancho Los Ángeles; pero en lugar de que Teófilo se dedique a hacer producir las tierras termina haciéndese cargo de cuidar a las empleadas de sus cuñadas, que 
están ahí castigadas. Al dar la orden de que si tratan de escapar Teófilo debe dispararles, éste mata a otras dos mujeres, que son sepultadas en el rancho. Es de esta forma que Teófilo y Eulalia son vistos después por las autoridades como parte activa de la red de prostitución de las Balandro.

La novela tiene, por lo tanto, una estructura cíclica y todos los involucrados en los actos delictivos voluntaria o accidentalmente reciben una condena. Incluso Simón Corona, quien confiesa que también formó parte de las actividades de las Baladro cuando fue a tirar dos cadáveres en una barranca. Sin embargo, como siempre es la falta de una respuesta rápida de Serafina y Arcángela lo que propicia su caída definitiva, pues en la novela se aclara que tuvieron posibilidades de huir antes de ser apresadas, pero que ambas desaprovecharon estas oportunidades. El incidente de la balacera en el Salto de la Tuxpana finalmente llega hasta Concepción de Ruiz exigiendo la detención de Serafina Baladro, a la que el narrador señala "en este caso no sabe uno de qué admirarse más, si de la tortuosidad o de la infalibilidad de la justicia", (131) refiriéndose a todas las vueltas que tuvo que dar el trámite antes de ser ejecutado. El descubrimiento de los cadáveres también es accidental, consecuencia del intento de soborno que Arcángela quiso dar al inspector Cueto, el cual despertó sus sospechas: cómo tanto dinero ante un hecho que no lo ameritaba para encontrarle solución.

\section{El origen del caos: conclusión}

No sólo se encuentra en la avaricia de las Baladro, sino también en las exigencias de las corruptas complicidades, a su vez codiciosas por la condición parasitaria de los extorsionadores. Finalmente, sin haberlo pretendido, Jorge Ibargüengoitia a través de las Baladro describió una típica historia empresarial, en donde todas y cada una de sus características corresponden a las circunstancias económicas, políticas y sociales de aquella aludida época comprendida entre mediados de los años de 1950 y de 1960. El afán emprendedor de las hermanas estaba motivado por su codicia y vanidad: el dinero y el prestigio (además de un deseo truculento de ejercer el poder). El entorno era propicio, porque con las dimensiones del pueblo chico las estrategias de la corrupción permitieron el establecimiento y operación del primer burdel; era un bajo perfil que podría haber permanecido 
inadvertido en la clandestinidad. Sin embargo, la avaricia de ellas y las exigencias de la corrupción trastornaron los afanes empresariales y el contacto con la realidad; en la contradictoriamente ficticia realidad del burdel, la particularidad del reglamento $u$ orden interno establecido a conveniencia de los intereses de las Baladro se pervirtió, al extremo de violentar el más elemental marco de la legalidad y de la moralidad.

Se puede decir, por lo tanto, que en Las muertas el dramaturgo y narrador concluye un ciclo de escritura con una crítica severa: todo el criminal conflicto surgió por codicia e ignorancia y se descubrió por casualidad, las víctimas recibieron una precaria compensación, mientras los ejecutores recibieron su castigo. Independientemente del desenlace, la novela plantea dos personajes femeninos de profunda complejidad, Serafina y Arcángela, quienes tienen distintas facetas y pueden mostrar diferentes tipos de afectos, pues si bien pueden experimentar amor, también son capaces de cometer las peores crueldades sin sufrir remordimientos. La existencia de estos grupos vulnerables, que se convierten en carne de cañón para el ejercicio de la prostitución, evidencia la falta de escrúpulos de sus familias y la pobreza, nociva combinación que siempre es la razón de la explotación y la vileza. Indefensas ante un mundo hostil, las empleadas están simbólicamente muertas antes de ser asesinadas, pues no existe para ellas ninguna posibilidad de huída, de mejoramiento o de redención. Al ser forzadas a convivir en condiciones extremas, la novela también revela bajas pasiones que se producen en el mundo femenino: la envidia, los celos o el resentimiento; todas estas circunstancias son un caldo de cultivo para el desastre, la abyección y el crimen.

\section{Referencias}

Aponte, B. (1990, Junio). Aspectos de narratividad de Las muertas de Jorge Ibargüengoitia. En Revista Hispánica Moderna. 43(1). 68-77

De la Colina, J. (1977, Noviembre). Libros. Las muertas. En Vuelta. 12, 40-41.

Domenella, A. R. (1989). Jorge Ibargüengoitia: de la ironía a lo grotesco. En Signos. Anuario de Humanidades. 153-160. 
García, M. (2002). Yo no soy humorista. En Cartas marcadas, 187-206.

Ibargüengoitia. J. (2002). El atentado y Relámpagos de agosto. Núm. 53, Madrid: Colección Archivos Allca XX Université de París X.

Ibargüengoitia. J. (2005a). Estas ruinas que ves. México: Editorial Planeta Mexicana.

Ibargüengoitia. J. (2005b). Las muertas. México: Editorial Planeta Mexicana.

Jalife, A. (2013, 24 de Diciembre). Ibargüengoitia o el desencanto. Confabulario. II, p. 6-10

Villaseñor, M. (2002). En primera persona, cronología ilustrada de Jorge Ibargüengoitia. (1928-1983), México: Senado de la República.

\footnotetext{
${ }^{1}$ La primera parte del análisis de la crisis de valores en la obra de Jorge Ibargüengotia fue publicado en el artículo "Jorge Ibargüengoitia o el crepúsculo de los valores", en Signos Literarios, Universidad Autónoma Metropolitana, p.p. 150-186, Volumen 12, 2017, también de Víctor Díaz Arciniega y Marisol Luna Chávez. El artículo se centra sobre todo en la producción teatral de Ibargüengoitia. Esta segunda parte de ese análisis muestra que las propuestas estéticas y axiológicas del autor se mantuvieron casi intactas.

${ }^{2}$ En la abundante hemerografía publicada sobre Jorge Ibargüengoitia también nos sorprende que mucha de la "crítica" se circunscribe a los márgenes de los efectos del humor, sin tomarse la molestia de indagar un poco más tanto en los recursos formales como en los efectos críticos; es decir, ni los tipos humanos ni los entornos sociales han sido objeto de alguna consideración medianamente amplia. En cualquiera de sus variantes, este es uno de los problemas del humor, que en sí mismo concentra la atención del lector / espectador, y nos hace difícil el adentrarnos en los propósitos ocultos tras el propio humor. En este artículo, nos proponemos rebasar ese convencional margen para explorar descriptivamente cómo Jorge Ibargüengoitia echó mano del sentido paródico y cáustico para soslayar el propósito crítico de su teatro y narrativa: ahí se dibuja con nitidez la dimensión social de la crítica que realizaba Jorge Ibargüengoitia. Los apoyos informativos y conceptuales más útiles para este análisis se encuentran en Jorge Ibargüengoitia (2002), en particular: Villaseñor (2002), García Flores, Sheridan y Escalante.

${ }^{3}$ En otra oportunidad abordamos esos asuntos, $v$. nuestro "Jorge Ibargüengoitia o el crepúsculo de los valores", en Signos Literarios y Lingüísticos, UAM-I, núm. 25, enero-junio, 2017, vol. XIII, pp. 144-179.

${ }^{4}$ Sin abordar de manera directa el asunto, $v$ : Aponte (1990), De la Colina (1977) y Domenella (1989)

${ }^{5}$ Aludimos a las farsas políticas Los relámpagos de agosto (1964), Maten al león (1969) o Los paso de López (1982), en donde el conflicto político se reduce a un enredo casi familiar; aquí, los recursos narrativos son linealmente convencionales y el empleo de la parodia sirve para atenuar el sentido crítico y reducir hasta la caricatura la grandilocuencia de la historiografía entonces al uso. En la obra dramática El atentado, Ibargüengoitia alcanzó su punto más alto en el dominio de la farsa; lo que en este sentido hizo después en su narrativa fue una discreta repetición de esa técnica. Jalife (2013) lo dice así: "A las explicaciones sociales, económicas o políticas [Jorge Ibargüengoitia] opone las trivialidades cotidianas: el equívoco, la torpeza, la ingenuidad preceden a los grandes acontecimientos."

${ }^{6}$ Vid. Díaz Arciniega y Luna Chávez (2017).

7 En diferentes momentos Jorge Ibargüengoitia refirió los tropiezos documentales y técnicos que enfrentó para la elaboración de su novela, como refieren Villaseñor (Jorge Ibargüengoitia, 2002, 404, García Flores, 2002, 418-19, y el propio Jorge Ibargüengoitia, 427-29).
} 